\title{
USING HIGH-TECHNOLOGY INSTRUMENTS TO ASSESS DEFECTS IN TREES
}

\author{
by Giovanni Nicolotti' and Paolo Miglietta ${ }^{2}$
}

\begin{abstract}
The technical features of instruments used to assess wood defects are described and opinions are expressed on their reliability, ease of use, and interpretation. The instruments include penetrometers, electrical conductivity meters, sonic and ultrasonic detectors, thermography, radar, and X-ray tomography.

Keywords. Tree stability; VTA; penetrometers; electrical conductivity; sonic and ultrasonic detectors; thermography; radar; X-ray tomography; hazardous trees, tree structure analysis.
\end{abstract}

Assessment of tree stability according to Mattheck and Breloer (1994) consists of 3 stages: visual inspection of the entire tree to look for external evidence of internal defects; detailed examination to see whether such defects exist and their extent; and instrumental measurement of internal defects and calculation of the residual strength. Elaboration of this method of analysis by Claus Mattheck has undoubtedly led to clarity by introducing scientifically demonstrated rules in a sector in which evaluation had always been based on personal experience. It has also encouraged the resumption of comparison and dialogue between researchers for the development of new instrumental investigation methods. The Pressler increment sampling borer/core extractor had been the only tool to assess wood decay for many years, but recently many new technologies have been developed.

This paper offers an overview of the devices currently on sale or under development. Their technical features are individually described and the results of our tests and those conducted by other researchers are presented.

\section{Penetrometers}

Three similar instruments originally designed for evaluation of the soundness of wooden structures can be found on the market: the Densitomat- 400 , the Resistograph, and the Sibert DDD 200. These are self-powered drills that insert a very thin probe at a constant, electronically controlled speed. The power demand of the motor during penetration expresses the density of the wood and is converted into graphic signals (dendrograms) that both reveal and quantify decay in the wood.

Densitomat-400 and Resistograph. These instruments are both commercially available. They consist of a sophisticated recording system that gathers up to 50 data per $\mathrm{mm}$ of forward travel. The geometry of the probe tip enables it to cut a hole wider than the $1.5 \mathrm{~mm}$ (0.06 inches) diameter of the shaft, which means that penetration is not influenced by resistance imposed by the walls of the hole. The bit does not extract the shavings, and the hole is left packed with compacted wood dust. Both devices are interfaceable with printers or personal computers and can carry drill bits from 30 to $150 \mathrm{~cm}$ (11.8 to 59 inches) long. These devices are also able to provide information on single growth rings and are commonly used in dendrocronology.

Sibert DDD 200. This commercially available instrument penetrates the wood more quickly than the Densitomat-400 or the Resistograph, but it provides fewer data per $\mathrm{mm}$. It carries bits 20 , 31 , and $40 \mathrm{~cm}(7.9,12.2$, and $15.7 \mathrm{in}$.) long, with a diameter of $1.27 \mathrm{~mm}$ (0.05 in.). It, too, provides a plot of the penetrability of the wood on a coaxial roll of millimeter-scale graph paper. Analysis is quicker with the DDD, and decayed areas within a tree can be reliably quantified, although the instrument cannot provide very detailed information about a single growth ring.

The above-described penetrometers are quite similar to each other; for this reason, advantages and disadvantages can be considered valid for all of them. The advantages of the various types of penetrometers are

- They furnish objective data that can be used to make uniform and standard quantitative assessments of decay. 
- The holes they make are small and are left filled with compacted wood dust, which means these instruments are classified as a nondestructive.

- The information they provide is both detailed and precise.

The disadvantages of penetrometers are

- Interpretation of a dendrogram requires much experience, especially in doubtful cases and when an assessment has to be made of a tree's physiological response to fungus infection (compartmentalization barriers, growth rings close together).

- The probes are slightly flexible. This means that they do not always run straight into the wood. They also can rub against the sides of the hole; the resulting friction can give a false reading.

- The data are confined to the path explored and offer no indication of the further vertical extension of any rot detected.

\section{Electrical Conductivity Meters}

Shigometer. The Shigometer is commercially available. First, a twisted pair of electrodes is inserted into a hole drilled into the trunk. An ohmmeter reads the wood conductivity from electrodes that are separated by about $1.5 \mathrm{~cm}$ ( 0.6 in.). Healthy wood gives values of about 400 to $500 \mathrm{k} \Omega$, whereas those for brown rot are in the range of 190 to $200 \mathrm{k} \Omega$. Values below $50 \mathrm{k} \Omega$ are regarded as highly critical (Shigo 1993).

The electrical resistance of wood is determined by its water content and its ion concentration. The Shigometer can thus provide an indication of a tree's physiological condition and vitality. However, apparently critical readings may also be given by healthy but very dry wood.

The advantages of the Shigometer are

- Analysis is nondestructive because holes made for the electrodes are very small.

- The instrument can evaluate the presence of decayed and discolored wood.

\section{Disadvantages are}

- Experience is required to interpret the readings.
- Before each measurement, the instrument has to be calibrated against a tree in the same physiological condition and known to be sound.

Vitamat. The Vitamat is commercially available; it provides a continuous, automated record of a tree's electrical conductivity. It consists of a bracket strapped to the trunk with 2 belts and mounted on a worm screw turned by a crank to drive 2 electrodes (connected with a ohmmeter) into the wood, to the trunk center, and provides a radial profile of its conductivity as determined by the ion concentration and water content. These 2 factors vary in function by the chemistry of the wood and its firmness (sapwood, heartwood, wet heartwood, or rot). This Vitamat is used to detect heart rot by Heterobasion annosum on spruce, but it works on all species of wood decay fungi. The healthy wood profiles of some species are so characteristic that they can be regarded as standards for comparison (Bucher et al. 1993).

The chief advantage of the Vitamat is that the device is not dependent on a supply of electricity, except for the battery of the ohmmeter. Its disadvantages are 1) that experience is required to interpret the readings, 2) the device is heavy and difficult to transport, and 3) the high pressure applied to drive the needles into the wood can cause deep wounds that do not always close at the point of entry. Wounds commonly occur on smooth-barked species.

\section{Sonic Detectors}

All sonic detectors, including the Metriguard hammer, work on the principle that transmissibility of sound waves through a body is determined by the body's density. Damaged wood is usually less dense because it has been rotted by fungi or tunneled into by xylophagous insects and therefore gives resistance signals that differ from those of intact wood.

The Metriguard hammer, which is commercial available, is a small, self-powered kit for measuring the speed of sound waves through the wood. The sound waves are generated by hitting the trunk with a hammer. Two sensors $(0.3 \mathrm{~cm}$ [0.12 in.] in diameter) are driven by hand or by a 
self-powered screwdriver into the bark opposite each other to a depth of 1 to $2 \mathrm{~cm}$ (0.4 to $0.8 \mathrm{in}$.). One sensor is struck with a hammer, and the speed at which the sound wave travels to the other sensor is determined by the density of the wood and its abnormalities.

The difference between the electronic hammer and a simple mallet is the quantification of the sound speed and not just the audible sound of wood. The tonality of wood changes only when there is extensive decay inside the trunk, but the speed of sound can also be influenced by small areas of decay or internal cracks that are not detectable with a mallet.

The advantages of the Metriguard hammer are

- The presence of abnormalities can be quickly revealed ( 2 to 3 minutes).

- A reliable distinction can be drawn between trees that are definitely sound and those requiring more precise investigation.

Its disadvantages are

- The hammer blow is not always the same intensity because the hammer is used manually. Thus, the wave front generated does not always have the same geometry. This means that resonance disturbances (secondary half-waves) may be generated inside the trunk and reach the opposite sensor, thereby disturbing the measurement.

- Doubtful cases always require further examination with more sophisticated instruments.

- The presence of all types of defects inside the trunk (holes, rots, cracks, insects) can be revealed, but the extent of the defects cannot be determined.

\section{Ultrasonic Detectors}

Ultrasonic detectors work on the principle that the transmissibility of ultrasound waves through a body is determined by the body's density.

Silvatest and Arbosonic. These detectors are both commercially available. The self-powered systems are composed of a computer, an automatic impulse generator, and a transmitted and reflected wave acquisition system.
Owing to differences in the resistance of air, bark, and wood, the sensors must be in direct contact with the wood. The Silvatest requires the stripping of small pieces of bark $(3 \mathrm{~cm}$ [1.2 in.] diameter), while the Arbosonic requires the use of adhesive putties (Sandoz 1994; Fujikura 1996).

The advantages of these ultrasonic detectors are 1) the tree species does not influence the outcome of the test, and 2) readings can be taken very quickly (1 to 2 minutes).

Disadvantages are 1) it is necessary to cut holes in the bark of the tree to apply the sensors (only with the Silvatest), and 2) the test reveals the presence of all kind of defects inside the trunk (holes, rots, cracks, insects) but not their extent.

Ultrasonic tomography. This apparatus, still in the experimental stage, is composed of several sensors that generate ultrasound readings. Sound waves are produced by impulse generators mounted on an elastic belt strapped around the trunk (Comino et al. 1998). Sets of diametrically opposite sensors are connected to an oscilloscope and a computer that analyses the waves to determine areas with the same density (Figure 1). This device can provide precise data for the entire cross section. It is completely noninvasive.

\section{Thermography}

Thermography is the measurement of radiant heat using an infrared camera (Catena 1992, 1993). The camera detects a 2- to 5.6- $\mu \mathrm{m}$ wavelength. The data are recorded on a diskette that can be read on a personal computer. The result is an image whose differences in color correspond to differences in temperature determined by the density of the wood and its water content. The sensitivity of the camera is on the order of $0.1^{\circ} \mathrm{C}$ between $0^{\circ} \mathrm{C}$ and $35^{\circ} \mathrm{C}\left(32^{\circ} \mathrm{F}\right.$ and $\left.95^{\circ} \mathrm{F}\right)$.

Because readings are always taken by comparison with a constant temperature, the device is calibrated to the ambient temperature gradient before each investigation. To ensure a uniform temperature throughout the trunk, it is better to work at night to rule out uneven irradiation effects of the sun. It takes about 10 minutes to scan an entire trunk, including the calibration procedure. 


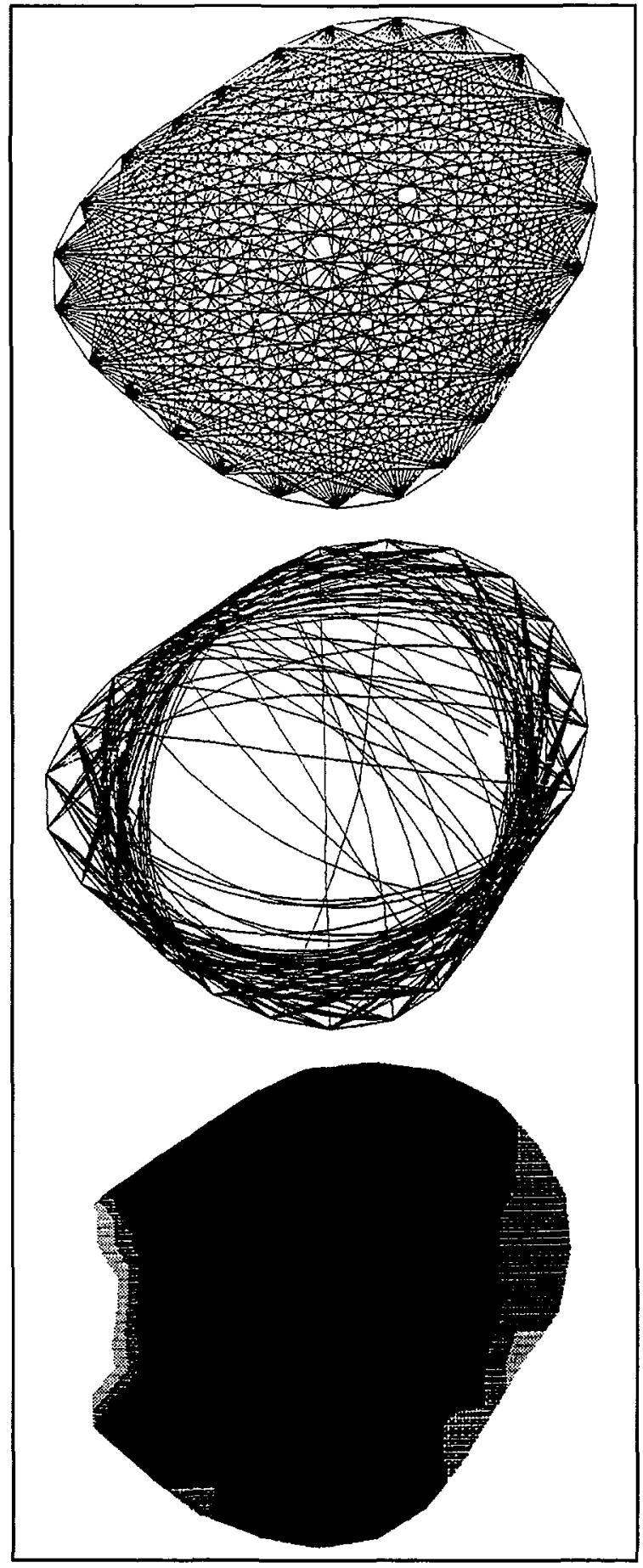

Figure 1. Plot of a sonic tomography analysis. The top picture shows the points at which the impulse generators, mounted on elastic belts, are applied. The middle pictures shows the theoretical tracing of waves. The bottom picture shows trunk areas with the same density, obtained by a PC-processing of the speed of the waves. In the bottom picture, the solid black areas show healthy wood (wave speed $>1,700 \mathrm{~m} / \mathrm{sec}[5,576 \mathrm{ft} / \mathrm{sec}]$ ), while the shaded areas indicate decayed wood (wave speed $<700-800 \mathrm{~m} / \mathrm{sec}[2,296-2,624 \mathrm{ft} / \mathrm{sec}])$. (Photo by ISMES-Arbotech.)

Advantages of thermography are as follows:

- It is a noninvasive method.

- The scanner can be swiveled to take in the whole of the trunk, and the real-time images on the monitor enable its state be immediately assessed.

- A general idea of the state of efficiency of the root system can be deduced from the images obtained when the tracer is employed at the base of the trunk.

Disadvantages are

- The equipment is rather expensive.

- Experience is needed to detect the decayed wood area on the thermograms.

- Thermography is better at measuring the temperatures of the external part of the trunk ( 3 to $5 \mathrm{~cm}$ [1.18 to $1.96 \mathrm{in}$.]), so it is able to detect large areas of decay or those diffused in the sapwood.

\section{Radar}

This echographic method is currently used to look for underground pipes. The information it supplies relates to electromagnetic characteristics rather than density. The application of this technology on assessment of wood defects is experimental.

A probe with 2 antennas, one to send the impulse and one to receive it, is passed around the circumference of the trunk to produce a conventional echogram coinciding with the perimeter of the trunk and providing a distorted representation of its cross-section (Figure 2). Radar is reliable for cavity detection but is less sensitive to variations in density. Echo waves from cavities are delayed by function of their size, and the data provide information about the entire section examined. 
Figure 2. Single-fold georadar section. The wave reflection is due to decayed wood inside the trunk.

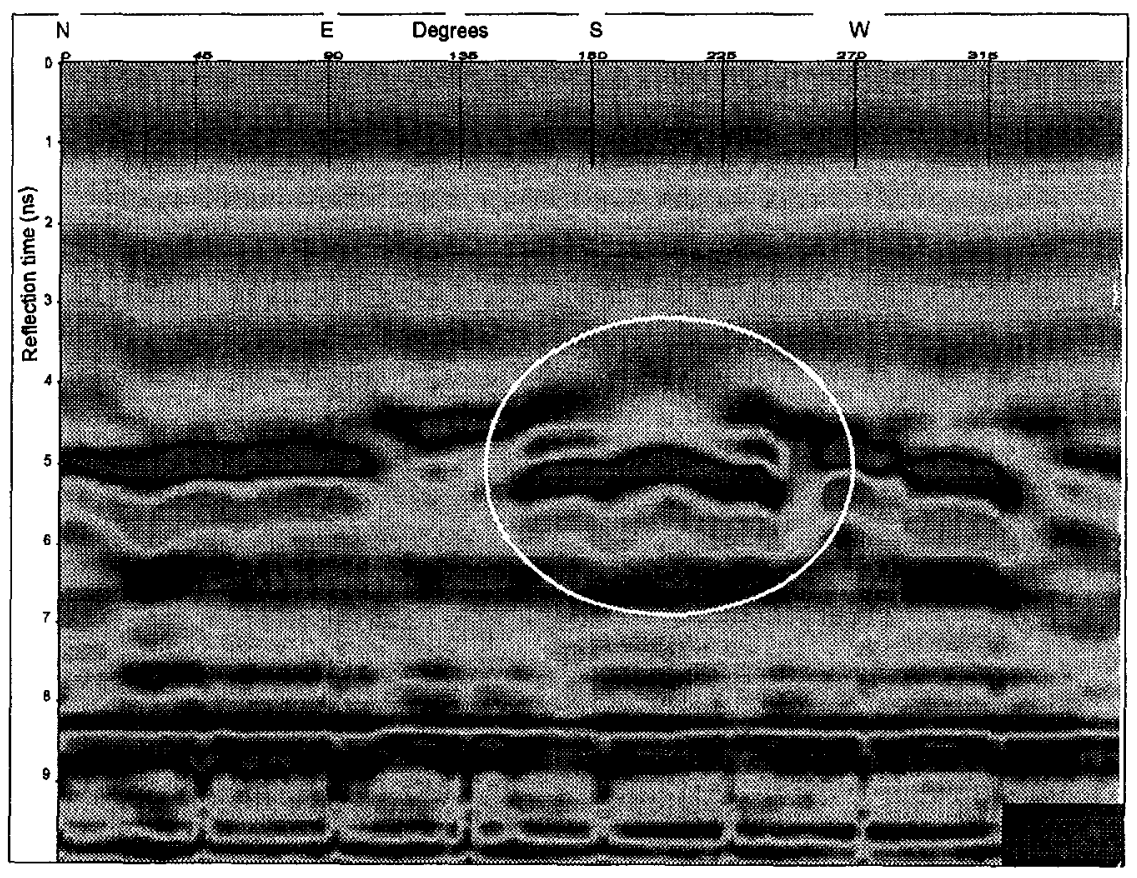

technologies that may one day be exploited for the assessment of trees in towns and cities.

\section{Decay-Sniffing Dogs: A Low-Tech Approach}

In contrast with the sophisticated techniques described above, a school in Sweden trains dogs to smell the presence of root rot and decay in standing woody plants (Davner 1986). A dog can unfailingly detect rot in anything from 5 to 10 ha $(12,500$ to $25,000 \mathrm{ac}$ ) of forest per day. The Swedish telephone service also uses dogs to check the condition of its poles. The use of decay-sniffing dogs in towns and cities may be

\section{Computed Tomography}

This well-known scanning technique, called a CAT scan, is used in medicine to gather sectional $X$-ray images of a body. It provides an image of a "tomos" or slice of a trunk for analysis. There is only 1 prototype in Europe of a device specifically designed to obtain measurements of trees. It is fully portable and has been tested in Hungary (Raschi et al. 1994).

When used on a tree trunk, these scans provide a complete map of wood density and moisture. The computer synthesis of the data from each section provides a true-scale picture of the structure of the trunk and reveals cavities or less dense parts of its wood.

The radioactive source is a caesium isotope. This means that introduction of the device into the European Union would be prohibited by the current legislation governing the use and transport of radioactive materials. Computed tomography is mentioned here for the sake of completeness, because apart from being extremely expensive and a unique prototype, its use represents an interesting example of the new limited by many odors much stronger than those given off by fungi. Indeed, the investigation of roots under tarmac and other street and pavement coverings would be impossible.

The advantage of using dogs to detect decay is that the method is nondestructive. Disadvantages are that it is a qualitative method only, and the training cost is expensive.

\section{Conclusions}

Application of diagnostic tools must be preceded and accompanied by thorough periodic visual inspection of a tree. Quick investigation with lowtechnology instruments such drills and mallets can usually differentiate structurally sound trees from those with extensive decay. When there is a doubt, then more-sophisticated instruments can be used to quantify the decay. High-technology methods should not replace the mallet but rather should complement its use.

We have found that such high-tech devices can often reach very high levels of precision and reliability. Interpretation of their data, however, must always be entrusted to an expert. Quite 
apart from this encouraging state of knowledge, however, there still remains the difficulty of monitoring the extent and soundness of a tree's root system. The fall of trees in towns and cities, indeed, is often caused by root rot fungi.

\section{Literature Cited}

Bucher H.P., L.J. Kucera, M. Walter, and K.J.M. Bonsen. 1993. Elektrische Leitwertprofile im Holzkörper mitteleuropäischer Baumarten, bestimmut mit dem "Vitamat." Mitteilungen der WSL, Band 68, Heft 2, pp. 65-144.

Catena, G. 1992. Une application de la thermographie en phytopatologie. Phytoma 439:46-48.

Catena, G. 1993. Utilizzazione di uno scanner termico per la diagnosi di cavità negli alberi. Riv. Ing. Agraria 2:67-75.

Comino, E., A. Quaglino, and L. Sambuelli. 1998. Cavità in onda. Acer 1:66-69.

Davner, L. 1986. Watch rot! Dogs in hunts for injured trees. Skogen 5:48.

Fujikura Europe Limited, 1996. New decay detection system uses ultrasound. Arb. News 5(4):32.

ISMES-Arbotech 1995. Fitopatie, vitalità e stabilità delle strutture arboree: Analisi tramite radar e onde soniche. Seminario Novembre 1995 Seriate.

Mattheck, C., and H. Breloer. 1994. Field guide for visual tree assessment (VTA). Arboric. J. 18:1-23.

Raschi, A., R. Tognetti, H.W. Ridder, and C. Beres. 1994. L'uso della tomografia computerizzata per lo studio degli effetti dell'inquinamento sulle piante arboree. Atti del convegno "Le piante $e$ l'inquinamento dell'aria: Aspetti biologici ed economici." Pisa 7-8 Aprile 1994. 64 pp.

Sandoz, J.L.J. 1994. Valorization of forest products as building materials using nondestructive testing. Ninth International Symposium on Nondestructive Testing of Wood. pp. 103-109.

Shigo, A. 1993. A New Tree Biology. Shigo \& Trees, Associates, Durham, $\mathrm{NH}$.
'DI.VA.P.R.A._Plant Pathology

University of Torino

Via L. da Vinci 44, I-10095 GRUGLIASCO

ITALY

${ }^{2}$ Comune di Torino-XIII Rip. Verde Pubblico Via Cottolengo 26, 1-10100 TORINO

ITALY

Résumé. On a conduit une description technique sur les principaux instruments employés pour évaluer les defauts du boi dans les arbres. De plus, ont été rapportées des évaluations techniques sur la crédibilité de caque instrument, sur la facilité d'employ et d'interpretation des données. Les appareils ont été décrits par group de fonctionnement technologique (pénétromètres, mesureurs de conductibilité éléctrique, mesureurs soniques et ultrasoniques, thermographie, radar et $\mathrm{X}$-ray tomographie).

Zusammenfassung. Die technischen Eigenschaften der wichtigsten Geraete zur Erfassung der Baumstabilitaet werden beschrieben und bezueglich Zuverlaessigkeit, Anwendbarkeit, Interpretierbarkeit der Resultate. Dabei werden die Geraete in Gruppen zusammengefasst, gemaess ihres Funktionsprinzips (Einstichmesser, elektrische Leitfähigkeit, Schall-/Ultraschallgeräte, Thermographie, Radar, X-Ray tomographie).

Resumen. Son descritos los rasgos distintivos de varios instrumentos usados para evaluar la estabilidad de los árboles y se expresan opiniones sobre su precisión, facilidad de uso, interpretación, costo y obtención. Los instrumentos son descritos de acuerdo a sus características tecnológicas (penetrómetros, medidores de conductividad eléctrica, detectores sónicos y ultrasónicos, termógrafos, radares y tomografía computarizada). 